\title{
PENGARUH KOMUNIKASI EFEKTIF TERHADAP KEPUASAN PELAYANAN RUMAH SAKIT ISLAM SITI RAHMAH PADANG
}

\author{
Dance Marsyandi Putra, Nazaruddin Aziz \\ Sekolah Tinggi Ilmu Ekonomi "KBP" \\ nazaruddinaziz@akbpstie.ac.id
}

\begin{abstract}
Effective communication is an important factor as a tool to serve the patients in order to realize satisfactory services for patients. When patients feel satisfaction when he served this will indirectly increase patient visits and hospital revenue. Effective communication has five basic components, namely respect, empathy, audible, clarity, and humble, these five factors will influence patient satisfaction with care RS.Tujuan this study to determine the effect of effective communication to satisfaction of RSI Siti Rahmah service in Padang. This research is an analytic research in the field of human resource management, effective communication with the independent variables consist of components respect, empathy, audible, clarity, and humble while the dependent variable is the RSI Siti Rahmah service satisfaction Padang. The population in this study are patients with RSI Siti Rahmah Padang many as 24662 patients. The sample in this study are patients with RSI Siti Rahmah Padang 100 patients as respondents sampling using sampling techniques Proportional random sampling. Univariate analysis by calculating the frequency distribution of each variable. While the bivariate analysis using multiple linear regression tests to measure simultaneously the independent variable on the dependent variable. The results of this study, to respect the independent variables did not significantly affect the service satisfaction in RSI Siti Rahmah (regression coefficient $=0.332$ and $p=3.32$ ). While the independent variable empathy also did not significantly affect the service satisfaction in RSI Siti Rahmah (regression coefficient $=0.150$ and $p=$ 15.0). While the independent variable audible significant positive effect on service satisfaction in RSI Siti Rahmah (regression coefficient $=0.077$ and $p=7.7$ ). While the clarity of independent variables are also significant positive effect on service satisfaction in RSI Siti Rahmah (regression coefficient $=0142$ and $p=$ 14.2). While the independent variable humble significant positive effect on service satisfaction in RSI Siti Rahmah (regression coefficient $=0511$ and $p=51.1$ ). Variable respect, empathy, audible, clarity, and humble which is a component of effective communication simultaneously significant positive effect on service satisfaction in RSI Siti Rahmah value supported by $F=7.146 p=0.000$ Advice from researchers to the leadership of RSI Siti Rahmah Padang to maintain and improve effective communication in the service process in RSI Siti Rahmah and is
\end{abstract}


expected to be able to innovate in implementing effective for communication to increase hospital revenue in the future.

\section{Keywords: Effective Communication, and Satisfaction Services}

\section{LATAR BELAKANG}

Komunikasi merupakan salah satu faktor yang menentukan kebahagian manusia, komunikasi juga faktor paling penting untuk menjalin hubungan,yang rapat dengan manusia lain. Manusia berkomunikasi karena ada beberapa tujuan yang hendak dicapai. Tujuan pertama individu berkomunikasi dengan mansia lain adalah karena individu tersebut hendak memahami orang lain. Individu hendaknya mengenali siapa mereka ,siapa diri mereka,apa yang mereka pikirkan, apa yang mereka rasakan dan macam macam lagi konteks kalimat berkenan dengan dirinya.

Komunikasi adalah proses penyampaian pikiran atau perasaan oleh seseorang kepada orang lain dengan menggunakan lambang lambang yang bermakna bagi kedua pihak, dalam situasi yang tertentu komunikasi menggunakan media tertentu komunikasi menggunakan untuk merubah sikap atau tingkah laku seseorang atau sejumlah orang sehingga ada efek tertentu yang diharapkan ( effendi, 2000:13).

Komunikasi harus dilakukan secara efektif agar komunikasi itu dapat mudah dimengerti oleh komunikan, komunikasi yang efektif dapat dilakukan apabila seseorang yang berkomunikasi memahami proses komunikasi efektif dan unsureunsur komunikais efektif. Komunikasi efektif merupakan komunikasi yang mampu menghasilkan perubahan sikap(attitude change)pada orang yang terlibat dalam komunikasi. Kita harus sadar akan pentingnya komunikasi khususnys komunikasi efektif, agar segala sesuatu yang kita tampilkan dan lakukan adalah komunikasi , maka penampilan dan segala sesuatu yang kita lakukan merupakan pesan. Adapun makna komunikasi yang efektif menurut effendi (2005) adalah komunikasi yang berhasil menyampaikan pikiran dengan menggunakan perasaan yang disadari . sedangkan menurut walter lippman dalam effendi (2005) bahwa komunikasi yang efektif adalah komunikasi yang berusaha memilih cara yang tepat agar gambaran dalam benak dan isi kesadaran dari komunikator dapat dimengerti, diterima bahkan dilakkan oleh komunikan.

Agar komunikasi menghasilkan komunikasi yang efektif,seseorang harus memahami prinsip prinsip dalam berkomuniaksi , ada lima prinsip komunikasi yang efektif ( The Five Inevitable Laws of Effective Communication). Dalam buku Make Yourself A Leader yang ditulis oleh Aribowo Prijosaksono dan Ping Hartono,yang harus dipahami. Lima prinsip dikembangkan dan dirangkum dalam satu kata yang mencerminkan esensi dari komunikasi tersebut yaitu REACH(respect, empathy, audible, clarity dan humble).yang berarti merengkuh dan meraih. Pada dasarnya komunikasi adalah upaya kita untuk meraih perhatian,cinta kasih ,minat, kepedulian,simpati,tanggapan,maupun respon positif dari orang lain.

Berdasarkan pada latar belakang pemilihan judul yang telah dikemukan diatas, maka penulis mengidentifikasi masalah dalam penelitian ini sebagai berikut: 
1. Apakah respect komunikasi efektif berpengaruh terhadap kepuasan pelayanan rumah sakit islam siti rahmah padang

2. Apalah empathy komunikasi efektif berpengaruh terhadap kepuasan kepuasan pelayanan rumah sakit islam siti rahmah

3. Apakah audible kumunikasi efektif berpengaruh terhadap kepuasan pelayanan rumah sakit islam siti rahmah padang

4. Apakah clarity komunikasi efektif berpengaruh terhadap kepuasan pelayanan rumah sakit islam siti rahmah padang

5. Apakah humble komunikasi efektif berpengauh terhadap kepuasan pelayanan rumah sakit islam siti rahmah padang

Tujuan Penelitian

1. Untuk mengetahui dan menganalisis respect komunikasi efektif berpengaruh terhadap kepuasan pelayanan rumah sakit islam siti rahmah padang

2. Untuk mengetahui dan menganalisis empathy komunikasi efektif berpengaruh terhadap kepuasann pelayanan rumah sakit islam siti rahmah padang

3. Untuk mengetahui dan menganalisiaudible komunkasi efektif berpengaruh terhadap kepuasan pelayanan rumah sakit islam siti rahmah padang'

4. Untuk mengetahui dan menganalisiclarity komunikasi efektif berpengaruh terhadap kepuasan pelayanan rumah sakit islam siti rahmah padang

5. Untuk mengetahui dan menganalisis humblekomunikasi efektif berpengaruh terhadap kepuasan pelayanan rumah sakit islam siti rahmah padang.

Manfaat Penelitian

Untuk menerapkan teori teori dan pengetahuan yang didapat dibangku kuliyah ke dalam masalah yang sebenarnya terjadi pada suatu perusahaan khususnya mengenai kuminikasi efektif , kepuasan pelayanan yang dilaksanana suatu perusahaan

\section{LANDASAN TEORI}

\section{Pengertian Komunikasi Efektif}

Komunikasi merupakan hal mendasar yang menjadi salah satu factor keselamatan pasien dan kepuasan pelanggan. Berbeda dengan komunikasi lainnya seperti komu nikiasi dibidang pendidikan,bisnis,dan lain sebagainya. Komunikasi efektif dalam bidang pelayanan rumah sakit memiliki tingkat kompleksitas yang cukup tinggi. Hal ini disebabkan komunikasi yang terlibat sangat banyak, informasi yang dibutuhkan sangat banyak,serta menyangkut dengan emosi pasien/keluarga pasien dan petugas kesehatan yang cukup tinggi.

\section{Proses Komunikasi Efektif}

"Proses komunikasi menurut Komala (2009:83) adalah proses aktivitas komunikasi terjadi manakala manusia berinteraksi dalam aktivitas komunikasi ,menyampaikan pesan mewujudkan motif komunikasi."

Suprapto (2011:5) menguntip Joseph A.Devito (1996) mengemukakan bahwa "komunikasi adalah transaksi ,dengan transaksi dimaksudkan bahwa 
komunikasi merupakan suatu proses dimana komponen komponennya saling terkait ,dan bahwa komunikatornya beraksi dan bereaksi sebagai suatu kesatuan dan keseluruhan."

Suksesnya proses komunikasi sehingga dapat menghasilkan komunikasi yang efektif tentu saja dipengaruhi oleh banyak faktor baik itu faktor komunikator maupun dari komunikan .faktor yang dipengaruhi antara lain :

a. Pesan yang dirancang dan disampaikan sedemikian rupa ,sehingga dapat menarik perhatian komunikan. Untuk merancang suatu pesan yang dapat menarik perhatian ini sebaiknya sebagai komunikator harus mencari tahu dulu karakteristik orang yang akan kita beri pesan. selain itu komunukator harus mempunyai kemampuan sebagai penyampai pesan yang menarik dan mudah dipahami.

b. Pesan harus menggunakan lambang lambang tertuju kepada pengalaman yang sama antara komunikator dan komunikan, sehingga sama sama mengerti, sebaiknya pesan disampaikan dengan beberapa metode dan tidak hanya secara lisan.pesan yang disampaikan dengan melibatna beberapa panca indera misalnya dapat dilihat, didengar,diraba akan lebih mudah dimengerti daripada pesan itu hanya disampaikan secara lisan.

c. Pesan harus membangkitkan kebutuhan pribadi komunikan dan menyarankan beberapa cara memperoleh kebutuhan tersebut. Jadi pesan harus sesuai harapan atau sesai kebutuhan penerima pesan. Pesan yang disampaikan akan terasa membosankan dan tidak ada arti penerima pesan apabila pesan itu tidak dibutuhkan.

d. Pesan harus menyarankan suatu jalan untuk memperoleh kebutuhan dimana komunikan digerakkan untuk memberikan tanggapan sesuai yang dikehendaki.solusi pemecahan masalah harus dikemukakan untuk dapat membantu klien keluar dari masalahnya.

e. Pesan yang dirancang dan disampaikan sedemikian rupa ,sehingga dapat menark perhatian komunikan. Untuk merancang suatu pesan yang dapat menarik perhatian ini sebaiknya sebagai komunikator harus mencar tahu duku karakteristik orang yang akan kita beri pesan. Selain itu komunikator harus mempunyai kemampuan sebagai penyampai pesan yang menarik dan mudah dipahami,

Komunikasi dapat dikatakan efektif apabila memenuhi tiga hal berikur :

a. Pesan dapat diterima dan dimengerti serta dipahami sebagaimana yang dimaksud oleh pengirim.

b. Pesan yang disampaikan oleh pengirim dapat disetujui oleh penerima dan tindak lanjuti dengan perbuatan yang diminati oleh pengirim.

c. Tidak ada hambatan yang berarti untuk melakukan apa yang seharsnya dilakukan untuk menindaklanjti pesan yang dikirim.

\section{Aspek kemampuan komunikasi efektif.}

Menurut Dedy Mulyana (2005:68), untuk dapat berkomunikasi secara efektif antara lain:

a. Komunikator

pengirim (sender) yang mengirim pesan kepada komunikan dengan menggunakan media tertentu. Unsure yang sangat berpengaruh dalam 
komunkasi , karena merupakan awal (sumber) terjadinya suatu komunikasi.

b. Komunikan

penerima (receiver) yang menerima pesan dari komunikator. Kemudian memahami ,meneterjemahkan dan akhirnya memberi respon.

c. Media

saluran (channel) yang digunakan untuk menyampaikan pesan sebagai sarana komunikasi. Berupa bahasa verbal maupun non verbal , wujudnya berupa ucapan,tulisan,gambar, bahasa tubuh,bahasa mesin,sandi dan lain sebagainya.

d. Pesan

isi komunikasi berupa pesan (message) yang disampaikan oleh komunikator kepada komunikan. Kejelasan pengiriman dan penerimaaan pesan sangat berpengaruh terhadap kesinambungan komunikasi.

e. Tanggapan

merupakan dampak (effect) komunikasi sebagai respon atas penerimaan pesan. Diimplementasikan dalam bentuk umpan balik (feed back) atau tindakan sesuai dengan

\section{Prinsip Dasar Komunikasi Efektif.}

a. Hukum Respect

Menurut Mahaguru Komunikasi Dale Carnegie dalam bukunya how to win friend and influence people, rahasia terbesar yang merupakan salah satu prinsip dasar dalam berurusan dengan manusia adalah dengan memberikan penghargaan yang jujur dan tulus. Seorang ahli psikologi yang sangat terkenal William james juga mengatakan bahwa "prinsip paling dalam pada sifat dasar manusia adalah kebutuhan untuk dihargai." Dia mengatakan ini sebagai suatu kebutuhan (bukan harapan ataupun keinginan yang bisa ditunda atau tidak harus dipenuhi), yang harus dipenuhi ini adalah suatu rasa lapar manusia yang tak terperikan dan tergoyahkan

b. Hukum Empaty (empati)

Menurut Stephen r. covey menaruh kemapuan untuk mendengarkan sebagai salah satu dari 7 kebiasaan manusia yang sangat efektif ,yauitu kebiasaan untuk mengerti terlebih dahulu ,baru dimengrti(seek first to understand -understands then be understood to build the skills of empathetic listening that inspires openness and trust). Inilah yang disebut dengan komunikasi empatik.

Empaty adalah kemampuan untuk menempatkan diri pada situasi atau kondisi yang tengah dihadap orang lain. Anda mampu merasakan apa yang dirasakan orang lain,sehingga komunikasi akan terjalin dengan baik sesuai dengan kondisi psikologis lawan bicara. Salah satu prasyarat utama dalam memiliki sikap empati adalah kemampuan kita untuk mendengarkan atau mengerti terlebih dulu sebelum didengarkan atau dimengerti oleh orang lain.

c. Hukum Audible

Menurut hukum REACH Makna dari audible antara lain dapat didengarkan atau dimengerti dengan baik jika empati berarti kita harus mendengar terlebih 
dahulu ataupun mamp menerima umpan balik dengan baik ,maka audible bearti pesan yang kita sampaikan dapat diterima oleh penerima pesan

d. . Hukum Clarity

Menurut hukum REACH Selain pesan harus dapat dimengerti dengan baik, maka hukum ini terkait dengan Audible adalah kejelasan dari pesan itu sendiri sehingga tidak menimbulkan multi interpretasi atau berbagai penafsiran yang berlainan. Karna kesalahan penafsiran atau pesan yang dapat menimbukan berbagai penafsiran akan menimbulkan dampak yang tidak sederhana.

e. Hukum Humble

Menurut hukum REACH yaitu Hukum kelima dalam membangun komunikasi yang efektif adalah sikap rendah hati . sikap ini merupakan unsure terkait dengan hukum pertama untuk membangun rasa menghargai orang lain, biasanya didasari oleh sikap rendah hati yang kita miliki, pada intinya antara lain,sikap yang penuh melayani (customer first attitude),sikap menghargai, mau mendengar dan menerima krritik,tidak sombong dan memandang rendah orang lain,berani mengakui kesalahan,rela memaafkan lemah lembut dan penuh pengendalian diri,serta mengutamakan kepentingan yang lebih besar.

f. Kepuasan Pelayanan (Y)

Pengertian Kepuasan

Menurut kotler kepuasan adalah perasaan senang atau kecewa seseorang yang timbul setelah mambandingkan kinerja produk yang dipikirkan terhadap kinerja yang diharapkan (Kotler dkk, 2007;177). Sedangkan Tse dan Wilton (1988) dalam Lupiyoado (2006) kepuasan atau ketidakpuasan pelanggan adalah respon pelanggan terhadap evaluaidaksesuaian yang dirasakan antara harapan sebelumnya dan kinerja actual produk yang dirasakan setelah pemakaiannya,

\section{Hubungan Antara Komunikasi Efektif dengan Kepuasan Pelayanan.}

Komunikasi dan kemahiran dalam berkomunikasi memerlukan proses pembelanjaran dan kesadaran komunikasi .komunikasi efektif pelayananan public adalah tindakan nyata yang bakan sekedar lips service saja. Dalam penyelenggaraan pelayananan, harus mengedepankan komunikasi yang persuasive dan menghindari komunikasi yang bersifat represif dan komunikasi dengan tatap muka akan lebih efektif ketimbang tanpa tatap muka.

Komunikasi yang efektif bisa tercapai bila dilakukakan dengan ikhlas dan totalitas yang mengedepankan kepentingan pelanggan. Kepuasan pelanggan adalah kepuasan penyelenggara juga, jika anggapan ini dijadikan roh pelayananan, maka akan tercapai bentuk pelayanan yang efektif dan efisien.

Dalam hal hubungan komunikasi efektif dengan kepuasan pelayanan,unsure unsure seperti komukator (penyelenggara pelayanan),komunikan (penerima pelayanan),isi pesan atau konten pelayanan ,prosedur pelayanan dan cara mengkomunikasikan produk pelayanan adalah unsure unsure yang berkaitan dan tidak dapat dipisahkan satu sama lainnya. Dalam hal ini bentuk komunikasi efektif adalah cara komunikasi terbaik yang dilakukan oleh penyelenggara pelayanan sehingga pesan yang disampaikan mudah terserap oleh penerima pelayanan dan sebaliknya penerima pelayanan dengan mdah dapat memenuhi persyaratan pelayanan tersebut tanpa adanya kesalahpahaman serta akurasi pelayanna yang diinginkan tepat waktu bahkan kurang dari waktu yang telah diterapkan 


\section{METODE PENELITIAN \\ Jenis Penelitian}

Jenis penelitian yang dilakukan dalam penelitian ini adalah penelitian survei, menurut Abdurahman (2011 : 16) penelitian survei adalah penelitian yang dilakukan terhadap sejumlah individu atau unit analisis, sehingga ditemukan fakta atau keterangan secara faktual mengenai gejala suatu kelompok atau perilaku individu dan hasilnya dapat digunakan sebagai bahan pembuatan rencana atau pengambilan keputusan. Penelitian survei ini merupakan studi yang bersifat kuantitatif dan umumnya survei menggunakan kuesioner sebagai alat pengumpulan datanya.

\section{Populasi dan Sample}

\section{Populasi}

Dalam penelitian ini populasi yang digunakan adalah pasien yang terdaftar sebagai pasien Rumah Sakit Islam Siti Rahmah. Berdasarkan data terakhir yang diperoleh dari rekapan data rekam medis, jumlah pasien yang terdaftar adalah sebanyak 24.662 pasien pada tahun 2015 di Polik linik Rawat Jalan.

\section{Sampel}

Sampel merupakan bagian kecil dari anggota populasi yang diambil menurut prosedur tertentu sehingga dapat mewakili populasinya Abdurahman (2011 : 129). Jadi sampel merupakan bagian dari populasi yang diambil melalui cara-cara tertentu yang juga memiliki karakteristik tertentu, jelas dan lengkap yang dianggap bisa mewakili populasi.

\section{Jenis dan Sumber Data}

Sumber data penelitian ini terdiri dari:

a. Data primer

Data primer yaitu data yang berasallangsung dari sumber data yang dikumpulkan secara khusus dan berhubungan langsung dengan permasalahan yang diteliti.Data primer dalam penelitian ini adalah data yang didapat dari jawaban responden terhadap rangkaian pertanyaan yang digunakan oleh peneliti.Sedangkan responden yang menjawab daftar kuesioner tersebut adalah pasien yang terdafta $r$ pada Rumah Sakit Islam SitiRahmah.

b. Data sekunder

Data sekunder yaitu data yang tidak diperoleh langsung oleh peneliti, tetapi diperoleh dari data yang diterbitkan olehrekammedis perusahaan, laporan suatu lembaga, studi kepustakaan, literatur, jurnal penelitian terdahulu dan majalah yang berhubungan dengan permasalahan yang diteliti, dalam hal ini data yang diambil adalah data pasien yang berobat di RumahSakit Islam SitiRahmah.

\section{TeknikPengumpulan Data \\ Observasi}

Observasi adalah teknik yang menurut adanya pengamatan peneliti baik secara langsung maupun tidak langsung terhadap objek penelitian (Umar, 2011:51).Pada penelitian ini penulis melakukan pengamatan langsung di RumahSakit Islam SitiRahmahuntuk mendapatkan data-data yang diperlukan sekaligus mencermati fenomena-fenomena yang berkaitan dengan penelitian ini. 


\section{Angket (Kuesioner)}

Teknik angket merupakan suatu pengumpulan data dengan memberikan atau menyebarkan daftar pertanyaan kepada responden dengan harapan memberikan respon atas daftar pertanyaan tersebut (Umar, 2011: 49).Dalam penelitian ini penulis mengajukan pertanyaan kepada responden dengan model pertanyaan yang bersifat tertutup dengan alternatif jawaban berupa skala.

\section{Uji Realibilitas}

UjiReliabilitasbertujuanuntukmenilaisejauhmanajawabandarikaryawandap atmemberikanhasil yang relative tidakberbeda (konsisten) biladilakukanpengukuranulangterhadapsubjek yang sama. Pengujian reabilitas dilakukan dengan menggunakan pendekatan Cronbach's alpha. Instrumen yang handal (reliable) apabilamemilikiCronbach's alpha. Lebihdari 0.985

\section{Teknik Analisa Data}

Supaya data yang telah dikumpulkan tersebut dapat bermanfaat maka harus diolah dan dianalisis terlebih dahulu sehingga dapat dijadikan sebagai dasar dalam pengambilan keputusan.Analisis data yang digunakan dalam penelitian ini adalah analisis kuantitatif dengan menggunakan SPSS 17.0.

\section{Analisis Deskriptif}

Menurut Bungin (2005 : 181) analisis deskriptif merupakan penelititan kuantitatif yang bertujuan untuk mendeskripsikan keadaan gejala sosial yang tampak dan melihat hubungan kausalitas antara gejala-gejala tersebut. Setelah data terkumpul kemudian disajikan ke dalam tabel distribusi frekuensi untuk dilakukan analisis deskriptif

\section{UjiAsumsiKlasik}

Pengujian asumi klasik dilakukan untuk mengetahui kondisi data yang ada agar dapat menentukan model analisis yang tepat. Untuk menguji apakah persamaan garis regresi yang diperoleh linier dan dapat dipergunakan untuk melakukan peramalan, maka harus dilakukan uji asumsi klasik yaitu:

\section{Uji Normalitas}

Uji normalitas bertujuan untuk menguji apakah dalam model regresi ,variabelpengganguatauresidumemilikidistribusi normal (ghozali,2006). Ada dua cara untuk mengetahui apakah residu terdistribusi normal atau tidak yaitu dengan analisis grafik dan uji statistic. Karena analisis grafik dapat menyesatkan ,maka dipilih uji stastik kolmogrov-smirnov dengan melihat tingkat signifikasinya. Uji ini dilakukan sebelum data diolah.Pendeteksian normalitas data terdistribusi normal atau tidak dengan menggunakan uji kolmogrov- smirnov. Residual dinyatakanterdistribusi normal jikanilaisignifikasikolmogrov- smirnov> 0.05 dansebaliknya.

\section{Uji Multikolinieritas}

Uji multikolnieritas bertujuan untuk menguji apakah dalam model regresi ditemukan adanya korelasi antar variable bebas (Djojo, 2011 : 66). Model regresi yang baik seharusnya tidak terjadi korelasi diantara variabel bebas. Jika variabel bebas saling berkorelasi, maka variabel-variabel ini tidak ortogonal adalah variabel bebas yang nilai korelasi antar sesama variabel bebas sama dengan nol. Multikolinieritas dideteksi dengan menggunakan nilai tolerance dan Variance Inflation Factor (VIF). Tolerance mengukur variabilitas variabel bebas yang 
terpilih yang tidak dapat dijelaskan oleh variabel bebas lainnya. Jadi nilai tolerance yang rendah sama dengan nilai VIF yang tinggi (karena VIF=1/ tolerance) dan menunjukkan adanya kolinearitas yang tinggi. Nilai cutoff yang umum dipakai adalah nilaitolerance 0,10 atau sama dengan nilai VIF dibawah 10.

\section{Analisis Regresi Berganda}

Analisis Regresi Berganda adalah suatu metode analisa yang digunakan untuk menentukan ketepatan prediksi dari pengaruh yang terjadi antara variabel independen $(\mathrm{X})$ terhadap variabel dependen $(\mathrm{Y})$.

\section{Uji t}

Uji t yaitu suatu uji untuk mengetahui signifikasi dari pengaruh variable independen terhadap variable dependen secara individual dan menganggap dependen yang lainkonstan. Signifikansi pengaruh tersebut dapat diestimasi dengan membandingkan antara nilai t table dengan nilai t hitung. Nilai t dapat diperoleh dengan mengunakan rumus (Irianto, 2010:204).

\section{Uji F}

$$
t_{k}=\frac{b_{i}}{S_{b i}}
$$

Uji $\mathrm{F}$ adalah untuk menguji adanya pengaruh variabel independen secara serempak terhadap variabel dependen.Aturan penolakan dan penerimaan uji $\mathrm{F}$, di mana kita akan menerima $\mathrm{H}_{0}$ jika $\mathrm{F}$ hitung lebih kecil dari $\mathrm{F}$ tabel dan menolak $\mathrm{H}_{0}$ jika F hitung lebih besar dari F tabel. Menurut Abdurahman (2011 : 230) rumus mencari F hitung:

\section{Koefisien Determinasi $\left(\mathbf{R}^{\mathbf{2}}\right)$}

Koefisien determinasi $\left(\mathrm{R}^{2}\right)$ dimaksud untuk mengetahui tingkat ketepatan paling tepat dalam analisis regresi dimana hal yang ditunjukan oleh besarnya koefisien determinasi $\left(\mathrm{R}^{2}\right)$ antara 0 (nol) dengan 1 (satu). Apabila koefisien determinasi nol, variable independent sama sekali mendekati satu, maka dapat dikatakan bahwa variable independent berpengaruh terhadap variable dependent. Apabila koefisien determinasi semakin mendekati satu, maka dapat dikatakan bahwa variable independent berpengaruh terhadap variable dependent, selain itu koefisien determinasi dipergunakan untuk mengetahui percentase perubahan variable tidak bebas, yaitu Kepuasan Pasien (Y) yang disebabkan oleh variable bebas yaitu respect $\left(\mathrm{X}_{1}\right)$, empathy $\left(\mathrm{X}_{2}\right)$, audible $\left(\mathrm{X}_{3}\right)$, clarity $\left(\mathrm{X}_{4}\right)$ dan humble $(\mathrm{X}$

\section{HASIL PENELITIAN DAN PEMBAHASAN Analisis data}

Pada penelitian ini dilakukan pengujian statistik yaitu pengujian reabilitas dan validitas untuk membuktikan tingkat keakuratan dan kevalidan data yang digunakan dalam penelitian, sebagaimana diuraikan sebagai berikut :

\section{Pengujian Validitas}

Uji validitas dimaksudkan untuk mengukur kuesioner yang digunakan sebagai instrumen penelitian, sehingga dapat dikatakan instrumen tersebut valid. Untuk mengetahui apakah sebuah pertanyaan valid atau tidak valid maka digunakan nilai pearson correlation yang dibandingkan dengan nilai $r$ tabel. Pada 
penelitian ini menggunakan 100 orang sampel, maka nilai $r$ tabel $=0.195$ untuk 2tailed (2 arah).

Bila nilai pearson correlation suatu butir pertanyaan lebih besar dari nilai $\mathrm{r}=0.195$ maka butir pertanyaan tersebut dinyatakan valid, dan bila nilai pearson correlation suatu butir pertanyaan lebih kecil dari nilai $r=0.195$ maka butir pertanyaan tersebut dinyatakan tidak valid, butir pertanyaan yang tidak valid tersebut akan dikeluarkan dan tidak digunakan/dipakai untuk mengukur sebuah variabel. Berikut ringkasan hasil pengujian validitas untuk masing-masing variabel penelitian.

\section{Uji Reabilitas}

Uji Reliabilitas bertujuan untuk menilai sejauh mana jawaban dari karyawan dapat memberikan hasil yang relative tidak berbeda (konsisten) bila dilakukan pengukuran ulang terhadap subjek yang sama. Pengujian reabilitas dilakukan dengan menggunakan pendekatan Cronbach's alpha. Instrumen yang handal (reliable) apabila memiliki Cronbach's alpha.

\section{Analisis Deskriptif}

Analisa ini bermaksud untuk menggambarkan karakteristik masing-masing variabel penelitian. Analisa ini bertujuan untuk memperoleh gambaran obyektif variabel meliputi nilai mean, standar deviasi, nilai minimum dan nilai maksimum.

Dalam deskripsi variabel penelitian ini penarikan kesimpulan dilakukan berdasarkan TCR (Tingkat Capaian Responden). Sebagaimana yang dikemukakan oleh (Riduwan, 2006 : 89)

\section{Uji Asumsi Klasik}

\section{Uji Normalitas}

Uji normalitas kolmogorov sminov adalah dengan membandingkan distribusi data yang akan di uji normalitasnya dengan distribusi normal baku. Distribusi normal baku adalah data yang telah ditranformasikan ke dalam bentuk Z-Score dan diasumsikan normal. Jadi sebenarnya uji kolmogorov smirnov adalah uji beda antara data yang diuji normalitasnya dengan data normal baku. Seperti uji beda biasa, jika signifikansi dibawah 0.05 berarti terdapat perbedaan yang signifikan, dan jika signifikansi diatas 0.05 maka tidak terjadi perbedaan yang signifikan.

\section{Uji Multikolinearitas}

Pengujian terhadap ada tidaknya multikolinearitas di dalam model regresi ini adalah ditunjukkan pada kolom tolerance dan VIF. Dengan asumsi, jika nilai $\mathrm{VIF}>10$, maka variabel independen mempunyai masalah multikolinearitas dan VIF $<10$ maka variabel independen tidak mempunyai masalah multikolinearitas.

\section{Analisis Koefisien Determinasi $\left(\mathbf{R}^{2}\right)$}

Analisis determinasi digunakan untuk mengetahui persentase sumbangan pengaruh variable independent secara bersama-sama terhadap variable dependen. Menurut Santoso, 2001 (dalam dwipriyatno, 2011) bahwa untuk regresi dengan lebih dari dua variable bebas digunakan adjust $\mathrm{R}^{2}$ sebagai koefisien determinasi

\section{Pengaruh Komunikasi Efektif Terhadap Kepuasan Pelayanan RSI Siti Rahmah Padang}

Berdasarkan hasil pengujian hipotesis menggunakan t-test, untuk variabel respect diperoleh nilai signifikan 0.045 , artinya nilai ini lebih kecil dari nilai alpha 
0.05. Berdasarkan analisis tersebut, komunikasi efektif berpengaruh positif signifikan terhadap kepuasan pelayanan di RSI Siti Rahmah Padang.

Komunikasi efektif yang dibahas dalam penelitian ini mengacu pada pengaruh komunkasi efektif terhadap kepuasan yang didefinisikan oleh Aribowo Prijaksono dan Ping Hartono dengan judul the five inevitable of laws of effective communication atau lima hukum komunikasi bahwa komunikasi efektif jika memenuhi syarat antara lain munculnya sikap respect, empathy, audible, clarity dan humble. Meningkatnya hubungan komunikasi efektif terhadap kepuasan pelayanan . hal ini relevan dengan prinsip komunikasi efektif yakni sebagai upaya meraih perhatian, pengakuan , cinta kasih maupun penghargaan terhadap diri dan lingkungan social.

Berdasarkan definisi pengaruh komunikasi efektif terhadap kepuasan pelayanan yang dikemukanan Aribowo Prijaksono dan Ping Hartono, lima hukum komunikasi yang efektif dapat diperoleh kesimpulan bahwa komunikasi yang efektif didalam nya muncul sikap respeck, empathy, audible, clarity dan humble.

Hasil penelitian ini sejalan dengan penelitian yang dilakukan oleh Maftuha (2010) tentang hubungan antara efektivitas komunikasi kepala sekolah dengan peningkatan motivasi kerja guru di MA DARUL Maaruf cipete Jakarta selatan.. Dengan menggunakn regresi linear berganda. Hasil penelitian tersebut menunjukan sebagian besar peningkatan motivasi kerja guru dipengaruhi oleh efektifitas komunikasi kepala sekolah. Penelitian yang juga sejalan dengan penelitian ini adalah hasil penelitian Muhammad ahdiyat (2013) dengan judul meningkatkan efektivitas komunikasi antar pribadi melalui layanan konseling kelompok pada siswa kelas V11 SMP Negeri 3 kendal tahun 2012-2013, dengan menggunakan metode analisis deskriptif kualitatif dan uji wilcoxon matchn pairs test.. Hasil penelitain menunjukan terhadap pengaruh efektivitas komunikasi antar pribadi dapat ditingkatkan dengan konseling kelompok

Berdasarkan penelitian ini didapatkan hasil bahwa komunikasi efektif berpengaruh signifikan terhadap kepuasan pelayanan Artinya, apabila komunikasi efektif dapat dipertahankan dan ditingkatkan ke arah yang lebih baik, maka akan dapat meningkatkan kepuasan pelayanan, begitu pula sebaliknya jika komunikasi efektif yang dijalankan tidak dapat ditingkatkan dan mengalami penurunan maka aka nada kecenderungan kepuasan pelayanan menjadi menurun. Menurut analisa peneliti, apabila komunikasi efektif dapat dijalankan dengan baik maka dapat meningkatkan kepuasan pelayanan di rumah sakit islam siti rahmah padang.

\section{SIMPULAN}

Berdasarkan hasil penelitian tentang Pengaruh Komunikasi Efektif Terhadap Kepuasan Pelayanan RSI Siti Rahmah maka dapat diambil kesimpulan sebagai berikut :

1. Respect berpengaruh positif signifikan terhadap kepuasan pelayanan di RSI Siti Rahmah sebesar 0.332 atau $33.2 \%$ dan nilai rata-rata skala TCR sebesar $71.47 \%$.

2. Empathy berpengaruh positif signifikan terhadap kepuasan pelayanan di RSI Siti Rahmah sebesar 0.150 atau $15.0 \%$ dan nilai rata-rata skala TCR sebesar $72.41 \%$. 
3. Audible berpengaruh positif signifikan terhadap kepuasan pelayanan di RSI Siti Rahmah sebesar 0.077 atau $7.7 \%$ dan nilai rata-rata skala TCR sebesar $34.2 \%$

4. Clarity berpengaruh positif signifikan terhadap kepuasan pelayanan di RSI Siti Rahmah sebesar 0142 atau $14.2 \%$ dan nilai rata-rata skala TCR sebesar $36.0 \%$

5. Humble berpengaruh positif signifikan terhadap kepuasan pelayanan di RSI Siti Rahmah sebesar 0.511 atau $51.1 \%$ dan nilai rata-rata skala TCR sebesar $51.0 \%$

6. Respect, Empathy, Audible, Clarity, dan Humble secara bersamaan berpengaruh positif signifikan terhadap kepuasan pelayanan di RSI Siti Rahmmah dengan nilai $\mathrm{F}=5.898$.

\section{DAFTAR PUSTAKA}

Fernandes, Y. D., \& Marlius, D. (2018). Peranan Customer Service Dalam Meningkatkan Pelayanan Kepada Nasabah Pada PT. Bank Pembangunan Daerah Sumatera Barat Cabang Utama Padang. https://doi.org/10.31227/osf.io/wrh3p

Marlius, D. (2018). Pengaruh Dimensi Kualitas Pelayanan Website Akademik Terhadap Kepuasan Mahasiswa Pada STIE “KBP”. Jurnal Ipteks Terapan. $\begin{array}{lllll}\text { Volume } & 12 . & \text { No. } & \text { 2. Hal. } & 116-128 .\end{array}$ http://doi.org/10.22216/jit.2018.v12i2.633

Marlius, D. (2018). Loyalitas Nasabah Bank Nagari Syariah Cabang Bukittinggi Dilihat Dari Kualitas Pelayanan. Jurnal Pundi. Volume 1. No. 3. Hal.1222. https://doi.org/10.31575/jp.v1i3.60

Marlius, D. (2016). Pengaruh Bauran Pemasaran Jasa Terhadap Minat Nasabah Dalam Menabung Pada Bank Nagari Cabang Muaralabuh. https://doi.org/10.31227/osf.io/vdqgx

Mayliza, R. (2019). Pengaruh Kesadaran Merek, Asosiasi Merek Dan Perception Of Quality Terhadap Keputusan Pembelian Hospital Bed Merek Paramout Di PT. Aga Medika Utama Padang (Studi Kasus Rumah Sakit Umum Kota Padang). https://doi.org/10.17605/OSF.IO/VYQ4E

Mayliza, R. (2019). Pengaruh Citra Perusahaan (Corporate Image) Dan Penanganan Keluhan (Complaint Handling) Terhadap Loyalitas Pelanggan (Loyality) Natasha Skin Care Di Kota Padang. https://doi.org/10.17605/OSF.IO/DF9XJ 
Safitri, R. N., \& Marlius, D. (2017). Penerapan E-Banking Dalam Meningkatkan Jasa Dan Layanan Perbankan Di PT. Bank Rakyat Indonesia Cabang Padang. https://doi.org/10.31227/osf.io/gkv8t

Susanti, F. W Ekazaputri. (2018). Service Performance Dan Kepuasan Sebagai Moderating Variabel Terhadap Loyalitas Nasabah Pada PT BPR Labuh Gunung Payakumbuh Jurnal Benefita: Ekonomi Pembangunan Manajemen Bisnis Dan Akuntansi. Volume 3. No. 3. Hal. 433444.http://doi.org/10.22216/jbe.v3i3.3472

Tiza, M. F., \& Susanti, F. (2019). Pengaruh Kualitas Pelayanan Terhadap Kepuasan Pelanggan, Studi kasus pada perusahaan JNE Cabang Padang. https://doi.org/10.31227/osf.io/hx87m 